
\title{
25 Research Square \\ Teaching And Learning In A Time Of Corona: A Social Work Experience
}

Roni Berger ( $\sim$ berger@adelphi.edu )

Adelphi University School of Social Work

\section{Research Article}

Keywords: pandemic, reflective journal, teaching during crisis, learning during crisis, coping

Posted Date: June 25th, 2020

DOl: https://doi.org/10.21203/rs.3.rs-37515/v1

License: (c) (i) This work is licensed under a Creative Commons Attribution 4.0 International License. Read Full License

Version of Record: A version of this preprint was published at Clinical Social Work Journal on April 3rd, 2021. See the published version at https://doi.org/10.1007/s10615-021-00804-0. 


\section{Abstract}

Preliminary results of a qualitative study of the lived experience of teaching and learning during the Covid-19 pandemic are presented. An instructor, a program director and five doctoral students in different stages of their coursework and dissertation proposal development, wrote a reflective journal. Participants varied in their levels of familiarity with technology-assisted education, personal backgrounds and circumstances including work, family and caring for sick relatives responsibilities. Participants' journals documenting their reactions, struggles and coping since the abrupt move of the university from face to face to online classes were content analyzed. The analysis was co-conducted by all participants to identify themes and generate understanding of the experience. Two main themes emerged from the analysis: A developmental process of participants' reactions, perceptions and meaning making of the experience and factors that shaped it. Lessons learned are discussed and recommendations for professional education and directions for future research are suggested.

\section{Background}

The global health crisis caused by the Coronavirus pandemic threw higher education throughout the world into a challenging arena forcing moving to an exclusively online mode on an unprecedented scale and at a rapid pace (McMurtrie, 2020). The fast and abrupt transition found schools, faculty, and students in diverse levels of preparedness to address the challenges involved and thus left students and faculty anxious, confused and deeply concerned (Fan et. al., 2020). Main issues included limited students' access to and mastery of technology, insufficient availability of technical support and guidance for faculty, and diverse attitudes towards a completely technology-mediated teaching and learning experience (McMurtrie, 2020). Further, some field-based courses that require experiential learning are more challenging in transitioning to the virtual world such as biology, chemistry and performing arts.

Social work education encountered during the pandemic additional unique issues due to the interactional relationship that is paramount in teaching practice, the diverse composition of the student body and the centrality of field work education. Much of the content in social work courses is designed to enhance students' practice skills development and requires experiential teaching strategies including role play and modelling applied with flexibility based on the instructor's assessment of the class and individual students needs at any given moment. Social work students are diverse with about one third non-whites and about $20 \%$ who self-identify as LGBT (Salsberg et. al., 2018); many carry multiple family and work responsibilities. Field education, which is a critical part of social work education was challenging because of university and agencies policies that banned face to face interactions with clients whereas opportunities for remote assignments in internships were limited. Additionally, some students were vulnerable to societal disparities and inequities exacerbated by the pandemic because they were called to provide care for sick relatives, find work to support their families who lost employment and income sources and DACA students awaiting a Supreme Court decision (Weissman, 2020) 
Studies to date examined processes, issues, challenges and strategies pertaining to distanced education and online learning in general (e.g. Dwivedi et. al., 2019; Schmidt et. al., 2013) and in social work in particular (Kurzman, 2019; Ouellette \& Westhuis, 2008). Limited literature, focused mostly on medical education (Lim et. al., 2009), addressed online teaching and learning at times of financial crisis (Chang, 2010), natural disasters (Collings et. al., 2019) and global health crisis such as the 2002-2004 SARS (Apple, 2010; Araújo et. al., 2020; Feast \& Bretag, 2005; McNaught, 2004; Patil, 2003; Wong et. al., 2007), Ebola, MERS and Zica outbreaks (Walsh et. al., 2018). No study could be identified regarding the experience of shifting to distanced learning in social work during a time of a global crisis. To address this gap, this article reports preliminary findings from a qualitative study of the lived experience of teaching and learning social work during the Covid-19 pandemic.

\section{Method}

Inspired by McNaught's (2004) who content analyzed staff's narratives in Hong Kong University during SARS and Alvarez et. al.'s (2005) analysis of narratives two faculty and two graduate student instructional designers who co-developed an online course, data were collected in a school of social work at an urban East Coast university from a female faculty (the first author) who initiated the project when the university announced moving to full online instruction, a female field education administrator who also teaches, four female and one male doctoral students in diverse stages of the program. Participant varied in the demographic characteristics, personal backgrounds and circumstances including work, school, family and caring for sick relatives' responsibilities and varied in levels of familiarity with technology-assisted education. The faculty was a war veteran in her country of origin, which lives in an on-going military conflict and the administrator had extensive experience in medical social work including hospital work through the AIDS, SARS, MERS and Ebola epidemics, in addition to flu and measles outbreaks, and working on critical incident teams.

Data were collected by reflective journaling, a strategy designed to capture how people make sense of the world and their operating within it (Boud, 2001). It involves participants' describing over a period of time a recent experience and unpacking its salient aspects. This method has been used to study the experience of school-to-work transition in recent mechanical engineering graduates (Lutz \& Paretti, 2019) and students' ability to engage in self-regulated learning (Wallin \& Adawi, 2018). No specific guidelines were given regarding the frequency and format of writing other than the general request that participants document their experiences and reactions during the rapid move of the university from face to face to online classes. Participants began writing their individual journals in late March 2020 until the end of the semester10 weeks later. This duration was within the timeframe deemed adequate for capturing significant experiences (Lutz \& Paretti, 2019).

The journals were content co-analyzed by five participants, yielding 35 analyses, with a high degree of agreement among coders. This method of analysis enhanced the credibility and rigor by means of triangulation (Krefting, 1991). Codes were compared and contrasted across participants and clustered into themes to generate understanding of the experience (Padgett, 2017). 


\section{Results}

The analysis of the journal entries suggest that compatible with the characteristics of a shared traumatic reality (Shamai, 2016), the experiences of students, instructor and administrator who were exposed to the same collective disaster mirrored each other. Two main themes emerged in all journals: A developmental process and factors that shaped it.

\section{A Developmental Process}

Three identifiable sequential stages flowing into each other emerged from the content analysis, although the timing and specific nature of each phase varied for individual participants. The stages were evident both in the pattern of posting and in the content of the entries. The number of entries varied greatly. With the exception of a student who posted a single entry, most students posted between nine to 16 entries, some students and the administrator posted a reflective summary, and the faculty posted nine entries.

Early Weeks: A Sense of Chaos. Journal entries in the first weeks tended to be frequent and relatively detailed. For example, the faculty posted four entries in one week. Everybody reported struggling with the need to abruptly change routines and learn to function on unchartered territory, which one student conceptualized as "trial by fire". Students who are practitioners had to move to providing services online, in addition to some emergency in-person services, which carried significant risk of exposure to the virus. The faculty needed to develop online versions of her courses, the administrator were engulfed by numerous meetings dedicated to developing alternative educational programs for students who could no longer intern in person as prat of the requirement of their professional degree. These rushed transition caused considerable uncertainty generating emotional reactions. A student shared

My head began spinning on $3 / 13$. From that point on, plans changed for managing work and Sunday School every couple of hours. We are considered essential employees yet plans had to be made for delivering services by telephone or video conference for every client while managing the phones (because support staff were sent home) and urgent appointments and reaching out for extra work to ensure clients had their health needs met (while how to do this changed daily as emergency regulations and policies had to be put into place).

Postings by all participants, irrespective to their role, revealed high levels of stress, anxiety, some to the degree of panic, and confusion. Students reported loss of motivation, productivity and concentration. Everyday stressors were amplified and mundane tasks felt insurmountable, exhausting and debilitating; e.g. "I was finding it difficult to even absorb information from an email and was exhausted... from caring for clients, making numerous adjustments daily and figuring out how to make life work.", "It's such an avalanche that normal activities seem like you're slugging through the mud." and "Working on a dissertation while working full-time remotely, teaching remotely, and holding private practice hours via phone with my clients is stressful to begin with but even more stressful to say the least because it was all within my home." The added challenge of "normal" tasks was mirrored in the faculty's posting "I was feeling the burden of responsibility, concerned that engaging students will be more challenging as they 
may be distracted by children, dogs, other occurrences in their home environment." The administrator compared the experience to previous crises, "It is not that is it a 'pandemic.' It is more than that. More profound. It is more than shared worry, fear, and onslaught of conflicting information. It is the collective trauma which is unmistakable." The faculty observed, "Everybody's stress level is sky rocketing. Instructors who never taught online panic, students are confused and the IT people are collapsing under the flood of demands, questions, calls for help, help with equipment." One student wrote "Everyone on the WhatsApp is talking about dropping out and I am nervous we won't have a cohort anymore". Writers conveyed a sense of being overcome by disbelief and living in an overwhelming chaotic reality. One student reported "I felt trapped and had nowhere to go". Another stated

The pandemic has brought up new problems for me; constant worry for my loved ones, the enmeshment of my personal and work space, and hunting down masks and gloves so I can leave my house with less anxiety...I had to do emergency [work-related] visits and contend with the fact that I might die and be okay with that on some level. I started taking my temperature daily and if I ordered anything, I would not open my door until the person left. I stopped going to see my mom because if I was carrying the virus, I could spread it to her and my brother and if she had it, she could spread it to me and my partner.

Entries documented personal and vicarious stressors. Personally, a student reported pressured by excessive irrational demands "I feel like I am expected to be available 24/7 for my clients, students, coworkers, boss and it is completely and utterly draining". Several students, especially those living alone, were anxious about the need to keep distance from loved ones and felt lonely, especially in important moments such as defending a dissertation proposal with no family or friends around "to provide a celebratory hug or high-five afterwards", celebrating alone Cinco de Mayo and birthdays. Capturing the spirit of multiple statements a student said "I am aware of feeling alone in all of this, I don't know if others are feeling the same way, or rather I can't trust they are (others have expressed similar frustrations, but I don't believe they are doing as poorly as I am)".

The faculty felt intimidated by the need to learn quickly new strategies and an added burden of having to perform in unfamiliar territory while maintaining all normal responsibilities that instructors have at all times. For example, an entry in the third week reads "Never did I learn a new skill with such intensity and such a short notice. This is intellectually, emotionally and physically challenging and sometimes draining." Faculty's concerns focused specifically on the challenges of engaging students who may be distracted by children and other family members, pets and other occurrences in their home environment as well as potential technological issues. Specifically, beginning entries by all reflected concerns regarding the use of technology. The faculty wrote

My main anxiety was about what can go wrong with the technology and how I can fix issues on the spot. Sure enough, in one of the first classes, I was working from two screens; one for the Zoom meeting and one for the PTT that I posted on Moodle to save me the challenge of going back and forth. The problem was that the screen with the PTT refused to allow me access. So here I was with a group of students who 
can see what I wrote in the PTT and a professor (me) who could not. After some looking around I was able to unblock the access. I believe that my sigh of relief could be heard far away.

Vicariously. Participants expressed anxiety related to family, clients, colleagues, friends and classmates. A student who was able to defend her dissertation proposal during the pandemic expressed feeling of guilt that classmates were forced to change their methodologies as well as sadness witnessing others struggling but not reaching out for help. Another student express feeling guilty for being safe and having the benefits of access to food unlike her clients and colleagues. "I would feel guilty at not being out there, not volunteering to help, and being cowardly for staying in my home while former colleagues were on front lines in the hospital." Faculty's entries reflected concerns about students' anxieties and its impact on their attendance and functioning. For example, one student shared feeling stressed by being moved to a supervisory role, for which she never received training. Another was absent for a couple of weeks and never responded to private emails, leaving the faculty conflicted between being intrusive by further attempts to reach out and respecting student's "no contact" implied desire. Eventually, the absence was explained by an apparently non-virus related hospitalization. Another student shared with the class prior to her virtual presentation her stress because her husband was lying sick with the virus in the other room and she felt torn between focusing on her presentation and the urge to constantly check on him.

Participants' own reactions to stress became stressors such as feeling guilt for their reactions; "Why am I not capable of absorbing new information? Two weeks ago I could but now not...But nope, couldn't think beyond the immediate and, brand new skills, forget about it." Acknowledging being objectively safe, a student shared

Everything makes me nervous. Everything. Why. It's like I'm sitting on a needle and I'm going to fall off. I have no idea. Things are fine... There's no problem in my immediate life. I'm nervous about standing up. I'm nervous while sitting. Blinking makes me nervous.

Stage Two: Struggling to Cope. Participants increasingly gained a realization of the magnitude of immediate and potentially long term challenges caused by the situation, leading to growing frustration, which was further increased by changes to established routines such as being notified about and able to attend a colleague's dissertation defense. One student shared that she got sick with the virus and was unable to work on the dissertation losing about three weeks of writing. Because all studies that involve personal interactions with research participants were temporarily suspended due to the pandemic, students were forced to revise approved and significantly developed research plans or opt to wait for an unknown future time when they can collect data in person. Both options involved significant loss of precious time and potentially financial cost, leading to feelings of disappointment, anger and despair. Some students became concerned of losing employment.

Technological issues continued for students and faculty. For example, in one class, a student disappeared from the screen but managed to inform the class via a text message that activating the camera leads to disconnecting her. A few minutes later, another student disappeared. Students asked to 
be excused from classes as they felt exhausted from struggling to cope with work requirements, school demands, family obligations and the general situation. The faculty wrote

I try to continue to focus on the presentation and students' reactions. I feel like I need five heads and numerous pairs of eyes and ears. A spare brain will also be nice. ... Teaching online and trying to attend to everybody's need is quite e daunting.

Concurrent with continuing to reflect challenges, entries also began to suggest evidence for gradually processing the experience, mourning the loss of people, the sense of safety and the familiar "normal" way of doing things and a struggle to cope with logistic and time management issues as well as yearning for and efforts to re-establish some familiarity, structure and stability; "Fingers crossed for a smoother week and things staying the same for more than 2 hours at any one time."; two students in the administrator's class expressed the desire to stay in class despite being ill with the virus because they needed familiar things. After responding briefly to her checking on how they were doing and how COVID touched their lives personally or professionally, one student said "can we move on - I need normalcy", to which the rest of the class agreed. Some students became proactive. One reported initiating an advocacy effort to address financial and logistic concerns resulting from the situation, "I was emailing, texting and speaking with them [other students] via phone", contacting the graduate student council, program and school administrators who themselves were struggling with a lot of unknown and constantly changing policies. A student offered the following image to capture the beginning of a gradual change

I feel my brain uncoiling like a snake being called out of its basket by a snake charmer, uncoiling, and becoming freer. This too was something I did not expect. Much of my brain is still tightly coiled in the bottom of the basket but there's a little bit that feels it can stretch. The periscope is going up for the first time and looking around.

Both the faculty and the administrator began to see manifestations of resilience. On week three, the faculty wrote

I am impressed with the level of engagement that students demonstrate and the empathy and support that they offer to each other. Real social workers. They seem involved, relate their Corona experience to the content of discussion and are very supportive of each other.

Similarly, the administrator reported that students' assignments manifested having pivoted from selffocused to client-focused

As the semester online progressed, I became more impressed by my students' resilience. At their own pace, they began to equate the learning in class with what they were experiencing, how it impacted their lives, and what other interventions might they use with clients to assist them in dealing with the anxiety and stress of COVID.

The observation was confirmed by some students "I actually feel space in my brain for new information. And I didn't before." The student described being able to move from focusing on her own experience to 
her professional mode

I wonder, is that how clients feel? It's not that l've not felt their pain. It's that I wonder whether they literally do not have room in their brain...for change, to be able to hear anything I'm saying, to think beyond the immediate, to think long term, to care for themselves. But for those clients who live in crisis, whether it's a product of their neighborhood, family, or a creation of self, is that how it is always?

However, the experience was not universal. One student who is also an adjunct faculty commented that the quality of her students and her own work had decreased.

Stage Three: Learning to Live in a "New Normal". Several weeks into the sheltering in place, some participants began to post shorter entries less frequently. Students began to indicate bouncing back and making adjustment to the new situation. Most entries reported lower levels of stress though one reported "We are now 9 weeks into the pandemic, and they [cohort members] are more stressed out than ever before." Some reported having "settled" into a new "normal" which is still crazy. Routines became more familiar. One student reported

I went into the office for a couple of hours for the first time today since March 20th. Had my temperature taken at the door, spritzed with hand sanitizer, mask of course, had my name taken down and admitted. Sat in my office with the door closed and felt weird when I encountered someone in the hallway. But got home unscathed. I guess this is the new normal.

Several students reported being able to focus better on their academic work as attending classes and thinking about school work became a refuge from the pressures outside. While recognizing performing below the usual level, a student stated "It is [a written assignment] a short one, and I don't feel great about the quality of it, but I do feel good about having gotten it done and about the prospects of doing more work." The administrator and the faculty began to notice changes in students' mood and manifestations of resilience. The faculty observed changes in academic performance

I am impressed with the ability of most of them to find the stamina for developing their presentations and facilitating class discussion... in today's class, students seem less anxious, more active and more involved. More students demonstrated familiarity with the material that was offered for reading.

The administrator concurred

As the semester online progressed, I became more impressed by my students' resilience. At their own pace, they began to equate the learning in class with what they were experiencing. ...For me, the gift in this tragedy, is trusting this group of students impacted by the pandemic can move the profession forward in a different manner. This generation will find new ways of knowing and of practicing.

Yet, concerns regarding the future prevailed and anxiety resurged for some regarding the prospects for reopening. One student was troubled as to how the near future will look professionally 
What will this [reopening] mean? Are we going to shake hands? Will I be in more danger? What happens when kids come back into the office? How do I get them to adjust AGAIN. No, we can't have that toy in here because I can't clean it between every client. No, we cannot have all of the siblings come in at one time because there's not enough room to social distance. No, we cannot fist bump.

The efforts to get back to functioning took its toll. The student commented "[I] Get 30-60 minutes done in the morning. The rest of the day I am too busy. I plan on doing it at night and by 9:30 I got nothing left in the tank." The student further expressed feeling guilty for taking time to do the work at the cost of fulfilling other tasks.

Student shared strategies that they used to bounce back. One stated "Well I caved and ordered the AirPod pros. I think part of it is the practical escape with noise canceling, and a large part of it is just perceived escape." The same student elaborated

I decided to spend time organizing my thoughts and the articles in a serious way, putting them in the order I think they make the most sense for the literature review, reading each article and taking notes, plugging that all into one document, and then begin to write the paper from there. I am not sure if this will take longer or not but at least I am moving forward and feel progress, which at this time feels good.

In addition to regaining some degree of functioning, students expressed exhaustion with the efforts and wish for the year to be over "it [writing a paper] was really more about survival than learning... I feel like this semester was just a waste and am kind of sad about that." While the sense of fatigue is not uncommon at the end of the semester, at this time the feeling had a different flavor. One student wrote

I am not looking forward to classes or my papers, which in the past I had pretty much been doing. School has actually taken the seat all the way in the back of the bus. I simply don't care. Not in the normal way of not caring, i.e. procrastination, but a deep prioritization of not caring. It feels like something extra that I simple don't need.

\section{Factors that Shaped the Process}

Entries identified factors that shaped the experience by either aggravating it or enabling and enhancing gradually moving into a coping mode.

Factors that Aggravated the Experience. Racism, limited institutional support, increased professional challenges and the nature of online learning were identified as stressors.

Racism. Non-white students conveyed that familiar exclusionary racist attitudes towards minority groups persisted and in some cases escalated although sometimes their expression was different. An Asian American student reported being spit on and being called a "corona bitch" while walking in public places. She further shared that a webinar on microaggressions that she attended was 'Zoom bombed' and the intruder wrote offensive racist vulgar comments in the chat area "It was very shocking and made me angry ... I have heard about this happening but never witnessed it before. It triggered feelings of trauma 
for me and a doctoral colleague who was on the webinar as well." A Black student felt helpless assisting Black clients who ask if it is safe to put on a mask due to worries about police brutality and hopeless in light of the disproportionate rates of Black and Brown people dying form COVID-19 related illness.

Limited institutional support. Students commented that their situation was aggravated by inadequate support from employers and the school. One student reported that her employer provided technological but not emotional support and she encountered institutional push back and a sense of exclusion. Some responses from the school were experienced as insensitive and unaccommodating. Several students who were concerned about financial burdens due to the situation reported responses from some administrators that were bureaucratic lacking empathy compassion, or understanding. Some students who rely on income from serving as adjuncts were worried that due to decreased enrollment they will not have a class and thus, will have a hard time paying their tuition.

Increased Professional Challenges. Students experienced cumulative effects of work-related role strain such as the need to move abruptly to delivering services via technology, meeting the needs of clients who were impulsive, with risky behaviors or with limited verbal abilities, and fulfilling additional tasks of other workers.

I would think about which clients had access to food or shelter. I would think about whether the shelter was a good place to go due to the number of COVID positive cases there. I would think about a client who typically would benefit from a nursing home referral but also had to keep in mind if I would be sending her to her death due to increase COVID related mortality rates in nursing homes...I would think about broken systems buckling under the amount of people applying for unemployment or public assistance. I would feel helpless in clients still waiting for EBT cards after almost a month and difficulty reaching an HRA representative for assistance.

The Nature of Online Learning. Several students felt that the abruptness of the transition and the changed interpersonal atmosphere of online learning added pressure and lacked the intimate direct context of face to face classes. One student stated

Online learning does not allow you to feel the energy from those interactions as you would when in person. Smiles are not as warm, nonverbal looks of agreement or distain are not as perceptible, and at times needed conversations among classmates are not readily available.

Others commented "I feel I would have had a much more positive experience if I was in the school and the meeting took place in person...I find that people tend to act differently when they are not hiding behind a screen." The same student continued "I also read body language VERY well, and felt I lost something as I could not look at my advisor [during a proposal defense] as much as I wanted to. All I saw were faces without body language." Another student wrote "I am tired of talking on the phone and looking at the screen." and yet another reported 
Online learning has forced me to be more attentive in class, so professors know I am engaging with the material. It has also forced me to be more deliberate with my time because I have more time and more energy to dedicate towards the assignments.

Factors that Enabled and Enhanced Gradually Moving into a Coping Mode. Participants identified that helping them were a sense of community, being active and proactive, support from friends and family, and faculty reactions

A sense of Community. Students reported that their cohort and other students provided a much needed emotional and instrumental support. A student reported that meeting remotely with other students was validating "to know we were not alone". A similar process occurred for faculty who reported working with the director of the center that trains and assists faculty and staff in integrating computer technologies into teaching "We developed a plan for triage and for allocating knowledgeable faculty and IT people to support those who are paralyzed by panic." One silver lining reported by most participants was getting a glimpse into others' lives beyond their formal roles, "Seeing them [students] with their children, dogs, family members was adorable, and it was nice to see them in their lives outside of the classroom."

Being Active and Proactive. Students were felt "unstuck" by initiating scholarly activities. One student shared "I presented [a webinar for doctoral students with NASW] with another doctoral student, and it was a great experience." Students reported that becoming proactive and negotiating with the university regarding financial and logistic implications of the situation on their status enhanced their feeling of battling helplessness and was empowering. Involvement with professional organization brought a sense of accomplishment and self-worth. "I received positive feedback from those who attended [a presentation]."

Support from Friends and Family. Several students reported that their family provided support at difficult moments. One commented on her reaching out when in an extremely stressful situation "I was freaking out. ...I called my mother. She kept me calm." Friends were an additional source of help "It was only after I reached out for support and wound up speaking with a doctoral friend/colleague who reached their hand down (figuratively) and pulled me up from the dark hole I felt trapped in."

Faculty Reactions. While students reported experiencing limited institutional support, individual faculty were sometimes helpful. One student wrote "I am particularly grateful for the advocacy, support, and availability of my advisor." Specifically, faculty's flexibility, availability and active reaching out, applying collaborative strategies and modelling were noted.

Flexibility. From the instructor's perspective, flexibility included an effort to accommodate demands without compromising quality of education. The faculty commented

I think that my welcoming students' participation at the level that their individual circumstances allowed, freed them from feelings of guilt, self-punitive and shame and allowed them to what one of them called 'a friendly together escape where I can forget for two hours the real world around me'. 
The sentiment echoed in students' reported experience. One student suggested that relaxing assignment deadlines helped and should be visited beyond the crisis situation as it enables students to work at their own pace.

Availability and active reaching out. Students commented on communication with faculty. For example, "This semester, I have spoken to professors via telephone or Zoom more than I have in the past"; "I received an email from one of my doctoral committee members who assured me that they are ready, willing, and able to be available for my dissertation proposal defense." Several students welcomed professors' contacting them between classes to check in and follow up regarding personal issues that they shared. One student felt that communication with a faculty member in relation to a frustrating administrative reaction was very supportive and helpful.

A collaborative process. Students' entries indicated that they experienced empowered, motivated and supported by the collaborative manner in which the faculty invited them to shape their plans for the course written assignments, negotiated structures, topics and dates that can work for them and their diverse circumstances.

Modelling. Students claimed that one factor that helped them being able to get back to work on their course materials was modelling by the instructor of coping at a challenging time.

\section{Discussion}

Content analysis of the journals indicated that compatible with conceptual and empirical literature about shared collective trauma (Shamai, 2016), the experiences of students, instructor and administrator mirrored each other. In agreement with common models of stress and coping (Berger, 2015; Littleton et. al. 2007), entries suggest a process of moving from an intense experience to a more accepting "new normal" and in some cases to manifesting resilience. The same progression has been documented in previous studies. For example, Tosone et. al. (2003) who, similar to the current project, analyzed the collected reflections of MSW students in NYC following the terrorist attack on September 11, described moving from a chaotic first stage to students' attempts to make sense of their feeling and eventually beginning to focus on their professional role. The experiences in the first stage that emerged from journals resonated with similar reports in previous studies such as Baum's (2010) observation that "the boundaries between the professional and personal realms may be blurred by both the intrusion of the personal world into the professional work and the intrusion of the professional work into the personal world" (p. 252). Similarly, Tosone et. al. (2003) reported that immediate students' reactions included shock, disbelief, bewilderment, loneliness, difficulty to concentrate, fear, anxiety, uncertainty, sorrow, depression, hopelessness, confusion, lack of motivation, helplessness and anger. Emotional reactions reported in the current project match those expressed in previous research, including the desire for normalcy, guilt for being relatively safe and enjoying own privileges (e.g. access to shelter and food) when others are hurting. Similar reactions were also observed in students during previous global health 
crises (e.g. Wong et. al., 2007). Also similar to previous research (Tosone et. al., 2003), at least one student shared that the current crisis reactivated in her struggles with anxiety earlier in life.

Social factors of structured and environmental racism, institutional growing demands and limited support, as well as the nature of online learning were reported to shape participants' experience. Racism and xenophobia can be fueled in reaction to public health, financial or security crises (Babacan et. al., 2009; Gopalkrishnan, 2013). Stigmatization and blaming epidemics on the "other" is a recurring historic narrative. "One dramatic aspect of epidemic response is the desire to assign responsibility. From Jews in medieval Europe to meat mongers in Chinese markets, someone is always blamed. This discourse of blame exploits existing social divisions of religion, race, ethnicity, class, or gender identity" (Jones, 2020 p. 1682). The journals of a black and an Asian student illustrate the multiple incidents of racism towards domestic and international of Asian descent reported during the recent COVID-19 outbreak (Logie, 2020). Institutional factors identified in this study as shaping the experience were similar to those quoted in previous research. For example, two studies designed to explore health care workers' perspective on working during an influenza pandemic in the United Kingdom (Aoyagi et. al., 2015; Ives et. al., 2009), reported lack of trust in the employing organization and the perception that employers do not take the needs of staff seriously, fail to provide accommodation and sufficient information and guidance. As in previous research (e.g. Fan et. al., 2020; Kurzman, 2019), limited familiarity and access as well as the absence of intimacy characterized the online learning environment as a factor impacting participants' experience. Similarly, in agreement with previous research (e.g. Collings et. al., 2019), factors contributing to adjusting to the new learning environment were instructor's flexibility and availability, support from classmates, family and friends and a sense of community.

The unplanned, spontaneous nature of the data is its strength and its weakness. The main strength is the authentic voices of individuals reporting their experiences as they are in the midst of living them, avoiding the challenges of memory selectivity and distortion encountered in retrospective studies. The main weakness is the lack of well thought through systematically organized process of collecting data.

This project is not free of limitations. First, participation was voluntary and thus, the entries reflect the voices of those who selected to share their experiences. A more comprehensive study can provide nuanced understanding of the reactions of faculty and students to shared traumatic exposure. Second, the abruptness and fast pace of events prevented planning a carefully designed process for data collection and analysis. McNaught's (2004) reflection on the nature of her study of narratives by staff at The Chinese University of Hong Kong about their experiences during SARS accurately applies to the current project

It is not a carefully planned research study. How could it be? SARS struck with frightening speed. There was no time to form an elegant multi-faceted evaluation plan in order to examine the changes in teaching strategies that teachers adopted. We all worked with very short time spans and with rapid revisions when plans went awry. (p. 194) 
Finally, the university where this project was executed is located in the urban epicenter of the pandemic in the US and the experiences of students and faculty may not be applicable to higher education institutes in different environments.

In spite the aforementioned limitations, some important lessons are offered. Universities and colleges need to develop a well taught through comprehensive protocol for institutional reactions to collective trauma designed to emotionally support students struggling with adversities. Such preparation is especially important in light of the predictions for recurrent global pandemics in the coming years. Many universities focused on enhancing faculty competence in online teaching. Not less important is training faculty in crisis readiness that includes skills and strategies for addressing students' reactions to distress and its impact on their ability to concentrate, focus and learn. Because of their professional and scholarly expertise on one hand and their membership in academia on the other hand, faculty in departments of social work, psychology, nursing and students counseling centers, especially those specializing in stress and trauma, are positioned in an ideal intersection for playing a major role in working collaboratively to develop a "response to disaster kit" for all faculty. Additionally, in light of the importance of social connections that emerged from the reflective diaries, structures for providing peer support, i.e. a "buddies system" is indicated.

Psychoeducation about trauma reactions should be provided to all students such that they are prepared and understand their own and their classmates' trauma reactions. Tosone et. al. (2003) found that students experienced as comforting and validating learning that many of their reactions were documented in relevant literature, thus feeling "normalized" by the universality of their reactions, ultimately feeling less anxious. Specifically, in universities with a diverse student body, like the one where this project was conducted, it is of utmost importance to make students aware of the role that racism plays in situations of trauma both because of multiple traumatizing experiences of minority groups and the racially-based disparity of access to services. This is critical when the stress related to the pandemic intersects with and magnified by the stress generated by other events such as the national anger and protests following the killing of an unarmed black man, George Floyd, by a white police officer, which occurred during the pandemic. Activities should be implemented to raise and reinforce awareness of the whole community including students, faculty, administration and staff to the tendency of racism and microaggression to intensify during crisis and training should be implemented of strategies to address them. Future research should examine productive measures for addressing students' and faculty's reactions during a global crisis and evaluate the effectiveness of diverse such measures.

\section{Declarations}

The study was exempt by the IRB.

All participants are co-authors of the article. The need for consent was moved by the IRB.

There is no conflicting interest. 


\section{References}

Alvarez, D. M., Blair, K., Monske, E., \& Wolf, A. (2005). Team models in online course development: A unitspecific approach. Journal of Educational Technology \& Society, 8(3), 176-186.

Apple, M. W. (Ed.). (2010). Global crises, social justice, and education. New York, NY: Routledge.

Araújo, F. J. d. O., de Lima, L.S.A., Cidade, P.I.M., Nobre, C.B. \& Neto, M. L. R. (2020). Impact of Sars-Cov-2 and its reverberation in global higher education and mental health. Psychiatry Research, 288, Article 112977, 10.1016/j.psychres.2020.112977

Aoyagi, Y., Beck, C. R., Dingwall, R. \& Nguyen-Van-Tam, J. S. (2015). Healthcare workers' willingness to work during an influenza pandemic: A systematic review and meta- analysis. Influenza and Other Respiratory Viruses 9(3), 120-130.

Babacan, H., Gopalkrishnan, N. \& Babacan, A. (2009). Situating racism: The local, national and the global. Newcastle: Cambridge Scholars

Baum, N. (2010). Shared traumatic reality in communal disasters: Toward a conceptualization. Psychotherapy Theory, Research, Practice, 47(2), 249-259.

Berger, R. (2015). Stress, trauma and posttruamtic growth: Social context, environment and identities. NY: Rutledge

Boud, D. (2001). Using journal writing to enhance reflective practice. In English, L. M. and Gillen, M. A. (Eds.) Promoting Journal Writing in Adult Education. New Directions in Adult and Continuing Education No. 90. (9-18). San Francisco: Jossey-Bass,

Chang, G.-C. (2010). Monitoring the effects of the global crisis on education provision. Current Issues in Comparative Education, 12(2), 14-20.

Collings, D. A., Gerrard, J. A. \& Garrill, A. (2019). Shaking up biology - our experiences teaching cell biology and biochemistry to a first year undergraduate class through the Canterbury (New Zealand) earthquakes. Journal of Biological Education, 53 (3), 236-249, DOI: 10.1080/00219266.2018.1472134

Dwivedi, A., Dwivedi, P., Bobek, S., \& Sternad Zabukovšek, S. (2019). Factors affecting students' engagement with online content in blended learning. Kybernetes, 48(7), 1500-1515.

Fan, Y., Wang, J., Jia, X, Liu, X., Song, Y. \& Zhang, L. (2020). The role of mental problem evaluation and intervention in university or college students kept at home due to serious Corona Virus Disease 2019 epidemic during high education. Pharmaceutial Care \& Research, 20(2), 81-91.

Feast, V., \& Bretag, T. (2005). Responding to crises in transnational education: New challenges for higher education. Higher Education Research and Development, 24(1), 63-78. 
Gopalkrishnan, N. (2013). From covert to overt: The role of crisis in transforming racism. In: Proceedings of the Third International Conference on Racisms in the New World Order: realities of culture, colour and identity (95-105). Third International Conference on Racisms in the New World Order: realities of culture, colour and identity, 29-31 August 2012, Cairns, QLD, Australia.

Ives, J., Greenfield, S., Parry, J.M., Draper, H., Gratus, C., Petts, J. I., Sorell, T. \& Wilson, S. (2009). Healthcare workers' attitudes to working during pandemic influenza: A qualitative study. BMC Public Health, 9, 56-56.

Jones D. S. (2020). History in a crisis - lessons for COVID-19. New England Journal of Medicine, 382 (18), 1681- 1683. https://doi.org/10.1056/NEJMp2004361

Krefting, L. (1991). Rigor in qualitative research: The assessment of trustworthiness. American Journal of Occupational Therapy, 45, 214-222. https://doi.org/10.5014/ajot.45.3.214

Kurzman, P. A. (2019). The current status of social work online and distance education. Journal of Teaching in Social Work, 39(4/5), 286-292. doi-10.1080/08841233.2019.1660117

Littleton, H., Horsley, S., John, S. \& Nelson, D. (2007). Trauma coping strategies and psychological distress: A meta-analysis. Journal of Traumatic Stress, 20(6), 977-988. doi:10.1002/jts.20276

Lim, E.C., Oh, V.M., Koh, D.R. \& Seet, R. (2009). The challenges of "continuing medical education" in a pandemic era. Annals of the Academy of Medicine, Singapore, 38, 724-726

Logie, C. H. (2020). Lessons learned from HIV can inform our approach to COVID-19 stigma. Journal of the International AIDS Society, 23(5), 1-3.

Lutz, B. D., \& Paretti, M. C. (2019). Development and implementation of a reflective journaling method for qualitative research. Proceedings of the ASEE Annual Conference \& Exposition, 9461-9475.

McMurtrie, B. (2020, March 29). The Coronavirus has pushed courses online. Professors are trying hard to keep up. Chronicle of Higher Education, 66(26), N.PAG.

McNaught,C. (2004). Using narrative to understand the convergence of distance and campus-based learning during the time of SARS in Hong Kong. Journal Educational Media International, 41 (3) 183193. doi.org/10.1080/09523980410001680806

Ouellette, P. M., Westhuis, D., Marshall, E., \& Chang, V. (2006). The acquisition of social work interviewing skills in a web-based and classroom instructional environment: Results of a study. Journal of Technology in Human Services, 24(4), 53-75.

Padgett, D. (2017). Qualitative methods in social work research. Thousand Oaks, CA: Sage.

Patil, N G. \& Yan, Y Chan Ho. (2003). SARS and its effect on medical education in Hong Kong. Medical Education, 37 (12), 1127-1128. doi:10.1046/j.1365-2923.2003.01723.x 
Salsberg, E., Quigley, L., Acquaviva, K., Wyche, K. \& Sliwa, S. (2018). New social workers: Results of the nationwide survey of 2017 social work graduates. Washington DC: The George Washington University Health Workforce Institute.

Schmidt, S. W., Hodge, E. M., \& Tschida, C. M. (2013). How university faculty members developed their online teaching skills. Quarterly Review of Distance Education, 14(3), 131-140.

Shamai, M. (2016). Systemic interventions in situations of collective and national trauma. NY: Rutledge.

Tosone, C., Bialkin, L., Campbell, M., Charters, M., Gieri, K., Gross, S., Grounds, C., Johnson, K., Kitson, D., Lanzo, S., Lee, M., Martinez, A., Martinez, M. M., Milich, J., Riofrio, A., Rosenblatt, L., Sandler, J., Scali, M., Spiro, M., \& Stefan, A. (2003). Shared trauma: Group reflections on the September 11th disaster.

Psychoanalytic Social Work, 10(1), 57-77. https://doi-org.libproxy.adelphi.edu/10.1300/J032v10n01_06

Wallin, P., \& Adawi, T. (2018). The reflective diary as a method for the formative assessment of self regulated learning. European Journal of Engineering Education, 43 (4), 507-

521.https://doi.org/10.1080/03043797.2017.1290585

Walsh, K., Sandars, J. \& Nordquist, J. (2018) Technology-enhanced learning for healthcare professionals: An essential response to infectious disease pandemics. British Medical Journal Simulation and Technology Enhanced Learning, 4, 1-3. doi.org/10.1136/bmjstel-2017-000236

Weissman, S. (2020). Coronavirus brings extra uncertainty for DACA students awaiting a Supreme Court decision. Diverse: Issues in Higher Education, 37(5), 6.

Wong, T. W., Gao, Y. \& Tam, W. S. W (2007). Anxiety among university students during the SARS epidemic in Hong Kong. Stress \& Health: Journal of the International Society for the Investigation of Stress, 23(1), 31-35. 